\title{
Childhood
}

\section{Touch in children's everyday peer relations in preschools}

\begin{tabular}{|r|l|}
\hline Journal: & Childhood \\
\hline Manuscript ID & CHD-19-0040.R3 \\
\hline Manuscript Type: & Original Manuscript \\
\hline Keywords: & children's peer-relations, embodiment, narrative, touch, preschool \\
\hline & $\begin{array}{l}\text { The article explores how touch appears in children's everyday peer } \\
\text { relations in preschools. The narrative research material consists of video } \\
\text { recordings produced in four Finnish preschools. Touch in children's } \\
\text { relations appeared as an invitation, an attempt to control and a } \\
\text { conventional pattern. The findings show that narrative environments of } \\
\text { the preschools produce, enable and limit touch in the children's everyday } \\
\text { peer relations. In terms of touch, children follow the practices created by } \\
\text { educators and the wider society. However, the children also challenge } \\
\text { these practices and the set limits, appearing as active agents in } \\
\text { producing embodied acts of touch in preschools. }\end{array}$ \\
\hline
\end{tabular}

\section{SCHOLARONE \\ Manuscripts}




\title{
Touch in children's everyday peer relations in preschools
}

\section{Virve Keränen, Elina Viljamaa \& Minna Uitto}

Faculty of Education, University of Oulu, Finland

\author{
Virve Keränen, Faculty of Education, University of Oulu, P.O. Box 2000, FI-90014 \\ University of Oulu, Finland, email: virve.keranen@oulu.fi ; Elina Viljamaa, Faculty of
}

Education, University of Oulu, P.O. Box 2000, FI-90014 University of Oulu, Finland, email:

elina.viljamaa@,oulu.fi ; Minna Uitto, Faculty of Education, University of Oulu, P.O. Box

2000, FI-90014 University of Oulu, Finland, email: $\underline{\text { minna.uitto@,oulu.fi }}$

Correspondence concerning this article should be addressed to Virve Keränen,

Faculty of Education, University of Oulu, P.O. Box 2000, FI-90014 University of Oulu,

Finland, Email: virve.keranen@oulu.fi 


\title{
Touch in children's everyday peer relations in preschools
}

\begin{abstract}
The article explores how touch appears in children's everyday peer relations in preschools. The narrative research material consists of video recordings produced in four Finnish preschools. Touch in children's relations appeared as an invitation, an attempt to control and a conventional pattern. The findings show that narrative environments of the preschools produce, enable and limit touch in the children's everyday peer relations. In terms of touch, children follow the practices created by educators and the wider society. However, the children also challenge these practices and the set limits, appearing as active agents in producing embodied acts of touch in preschools.
\end{abstract}

Keywords: children's peer relations, embodiment, narrative, preschool, touch 


\section{Introduction}

Children stand hand in hand in a queue in the corridor of a preschool. A group music session is about to start in the music room. Milla (the educator) hurries Anniina and Thomas, who are still playing in another room.

Milla: Anniina and Thomas, I'm waiting for you!

The children run to Milla.

Milla: Anniina and Thomas, you can come and hold my hand.

Milla, Anniina and Thomas walk hand in hand first in the queue; the other children are [insert Figure 1] walking behind them. Iiro, who is holding hands with Sara, touches the toys that are lying on the floor near where they are walking. Iiro jumps and bends to get the toys, but he doesn't let go of Sara's hand.

The above fragment is an example of a moment of touch taking place in everyday life in a preschool. This article uses such moments to deepen the theoretical understanding of touch in children's peer relations. In this article, touch is understood in a holistic way: It is an embodied act towards someone or something. In addition, touch is seen as a manifold phenomenon, since it is physical movement that is shaped by the culture and through which social relations can be created (Classen, 2005; Fulkerson, 2014).

Research has established that touch plays a significant role in human lives: People communicate and gain vitally important information from the environment via touch (e.g. Field, 2014; Paterson, 2007). Moreover, the anthropological research on touch has suggested that the ways in which touch is manifested in society are created in a process, wherein the communal history should be considered; for example, the Finnish touching culture has been 
described as evasive or violent as a result of wars, poverty and the country's agrarian history (Kinnunen and Kolehmainen, 2018).

Children's peer relations have been studied extensively (e.g. Corsaro, 2015), but these studies mainly lack focus on touch with few exceptions. For example, the psychologically oriented study of Cigales et al. (1996) discusses which body parts children touch, how and why children touch each other and how they respond to touch. In addition, there are a few studies focusing on touch in the relationships and interactions between children and adults (Cekaite and Bergnehr, 2018; Keränen et al., 2017). Touch has also been studied from the perspectives of its physiological effects on premature babies (e.g. Mäkelä, 2005) and on children's development and wellbeing (Carlson and Nelson, 2006; Field, 2014). These studies emphasize that caring relations can be created between children and adults through physical closeness and touch (see also Aslanian, 2018; Hännikäinen, 2015). In this article, our research question is as follows: How does touch appear in children's everyday peer relations in preschools?

\section{Touch as a part of children's embodied relations}

Previous research lacks focus on touch in children's peer relations in preschools. Instead, the research has focused on children's peer culture (Corsaro, 2003), children's language and interactions (Cekaite and Björk-Willén, 2012), closeness and difference in peer relations (Jensen, 2018), the meaning of belonging and togetherness (Hännikäinen, 2018; Juutinen et al., 2018) and bullying (Repo and Repo, 2016). Touch is present in the findings of these studies, but it is not the focus. For example, Juutinen et al. (2018), who studied the politics of belonging, noticed that children construct belonging and exclusion via touch. Studies on rough-and-tumble play also show how physical interactions like wrestling and hitting one 
another can be viewed as a space where children can experiment with how to be in touch with each other (Peterson et al., 2018). In addition, Cekaite's (2018) study illustrates that touch and language are intertwined in children's interactions, while Jensen (2018) describes how children show closeness to each other by hugging or sitting near each other, whereas distance is shown through bodily distance.

Touch is a part of everyday lives in preschools. The Finnish National Core Curriculum for Early Childhood Education and Care (2018) guides the practices and pedagogy in preschools: This document explicitly states that touch is a part of nurture and care. This is significant to note, since an emphasis on touch as a part of nurture and care suggests that touch happens only from an adult towards a child. Hence, there is a risk that children are seen only as objects of touch rather than subjects. Seeing the adult as the one who nurtures, cares and controls children's bodies is understandable, since traditionally, the aim of educators has been to guarantee that children remain physically safe in preschools (Lupton, 2012). According to Valentine (2009), this protection of children's bodies aims to instil proper, productive citizenship. A body that is unharmed indicates well-being, and as Christensen (2000: 48) writes, 'the child may become a symbol of adult creation and a moral statement of adult achievements'.

Here, we understand children as active agents in their social worlds, also in terms of touch in their peer relations (Alanen, 2010; Prout, 2000). Agency is not something given to children by adults, but continuously constructed in the versatile relations that the children have (Rautio, 2013) in the institutional context of the preschool. Preschools are constructed by adults for children (Rasmussen, 2004) and form a significant field where children learn the rules and habits of how to be and live with each other. Rules and habits regarding touch are constructed as part of the culture (Classen, 2005). Families' and preschools' cultures of touch 
encounter in preschools, which makes them interesting environments to study touch in children's peer relations.

According to Merleau-Ponty (1962), the essence of being is embodiment: People perceive the world in and through their bodies. When studying touch in children's peer relations, we emphasize these relations as embodied and that the environment matters in which children encounter as bodies (Grosz, 1994; Merleau-Ponty, 1962; Welsh, 2013). Our understanding of relations as embodied stems from the concept of interembodiment (Lupton, 2012). Lupton (2012) studies the concept of interembodiment in the context of childhood and leans on Merleau-Ponty's (1962) concept of intercorporeality. Interembodiment refers to the notion that bodies are connected to other bodies (Lupton, 2012; Springgay, 2008). This connectedness, as we see it, refers to the understanding that children come to exist via their bodies to themselves and others in their everyday relations. Although people are in the world through their own bodies, there are also similarities in their embodied experiences of the world (Welsh, 2013). Recognizing these similarities enables people to understand others, connect and construct relations; touch is one way to perceive and process knowledge about the world, self and others (Merleau-Ponty, 1962).

Touch is an act of interembodiment (Springgay, 2008: 23-31). At the same time, it is both private and social (Manning, 2007); both the one who is touched and the one who touches become touched (Merleau-Ponty, 1962). This reciprocal nature of touch makes it a strong form of communication. However, how strong a message is passed on by touch depends on how the touch resonates in the body. Merleau-Ponty (1962: 316) writes, 'I am able to touch effectively only if the phenomenon finds an echo within me [...]'. Grosz (1994) points out that touch does not extend only to the material form of the body but also touches people's inner worlds and creates a relation between those involved. 


\section{Research material and the methodological starting point}

The research material consists of video recordings (altogether, 26 hours), which were produced in four Finnish preschools with groups of children aged 1-6 with diverse backgrounds. The videos were recorded in autumn 2013 as part of two larger projects. ${ }^{1}$ The video recordings did not focus on touch explicitly, but on everyday situations in preschools. Elina, one of the authors of this article, was one of the researchers recording the videos. As the moments of touch occurred in preschools, educators were present, who could be early childhood education teachers or childcare workers. For ethical reasons, we use the term 'educator' for all these adults and do not distinguish anyone's exact professional status. In addition, all the names used for people and preschools are pseudonyms. Ethical issues were closely paid attention to in the larger projects; for example, the conditions and permissions of video recording children was considered carefully (Palmadottir et al., 2018). We committed to these ethical choices made.

We employ a narrative approach in our research. We understand the moments of touch in preschools as small stories, defined as fleeting moments in children's everyday lives (Bamberg and Georgakopoulou, 2008). In addition, we see that, during these moments of touch, children make sense of themselves, each other and the world around them (lisahunter and emerald, 2017). Furthermore, we understand these small stories as being more than verbally constructed (Puroila, 2013). We have been inspired by Merleau-Ponty (1993), who does not distinguish between verbal and embodied telling, but instead, comments that all humans have a common desire to express and reach out to one another. Hence, small stories can be told both through and in the body (lisahunter and emerald, 2017).

\footnotetext{
${ }^{1}$ From exclusion to belonging: Developing narrative practices in day care centers and schools (BELONG) research project: 2013-2015, project number 264370, Academy of Finland; Values education in Nordic preschools: Basis of education for tomorrow (ValuEd) - research project: 2013-2015, project number 53581, Nordforsk.
} 
It must be noted that these small stories have been constructed in particular narrative environments, including the intertwining relations in preschools (Gubrium and Holstein, 2008; Ochs and Capps, 2001). The narrative environment produces and enables certain stories (Gubrium and Holstein, 2008; Hohti and Karlsson, 2014), and in this research, this environment encompasses the peer relations, materiality and the institutional context and culture of the particular preschool, as well as the wider culture and society.

In the recordings, Virve found a total of 56 moments of touch that varied in length from a few seconds to several minutes. The analysis of these moments was an inductive process and did not proceed systematically from one phase to another; instead, different ways of analysing overlapped. Virve then wrote the moments of touch in the form of small stories (Bamberg and Georgakopoulou, 2008), providing the detail of what happened in each moment.

After the moments of touch had been written in the form of small stories, Virve utilized holistic reading (Lieblich, 2014; Riessman, 2008). She read the small stories as a whole and gave each story a title. Next, she applied heuristic analysis (Georgakopoulou, 2015) to them by paying attention to the following: 1) the ways of touch (how the children touched each other, and how the touch emerged between the children), 2) the sites in the preschools where the children touched each other and 3) who was present, what kind of agency appeared and what the touch did.

During the third phase of the analysis, Elina and Minna joined the process and read the small stories. At this stage, we returned to the video recordings. The analysis process went back and forth between the written small stories and recordings (Palmadottir et al., 2018). In this analysis, we paid attention to the narrative environment of the children's touch. After several rounds of reading the small stories and watching the recordings, we established that 
touch in children's peer relations appeared 1) as an invitation, 2) as an attempt to control and 3) as a conventional pattern (see Table 1).

Touch is a phenomenon that is hard to express through the written word alone. Hence, we use drawings based on the video recordings to illustrate the small stories of touch in the 'Findings' section.

Table 1. Moments of touch

\begin{tabular}{|l|l|l|l|l|}
\hline The preschool & $\begin{array}{l}1 . \text { Touch as an } \\
\text { invitation }\end{array}$ & $\begin{array}{l}\text { 2. Touch as an } \\
\text { attempt to }\end{array}$ & $\begin{array}{l}3 . \text { Touch as a } \\
\text { control }\end{array}$ & A total of small \\
& & 5 & - & stories \\
\hline Lilies & 26 & 2 & - & 11 \\
\hline Roses & 6 & 3 & 7 & 28 \\
\hline Maples & 1 & - & - & 16 \\
\hline Anemones & 38 & 11 & 7 & 56 \\
\hline A total of small & & & & 1 \\
\hline stories & & & & \\
\hline
\end{tabular}

\section{Findings}

\section{Touch as an invitation}

Firstly, touch in children's relations appeared as an invitation in different types of situations in preschools as children invited each other to play and to be together via touch. The following story is from the Lilies preschool and a group of children aged three to five years. The children have gathered for circle time just before lunch. 


\section{Ville and Miska}

Two boys named Ville and Miska sit next to each other on a bench during circle time. Anu (the educator) is teaching a poem. Suddenly, Miska places his head in Ville's lap. Ville presses his chin into Miska’s temple. Miska sits up and holds his hand to the spot where Ville pressed his chin.

Anu: Let's clap hands!

All the children except Miska start to clap their hands to the rhythm of the poem they are repeating out loud. Miska presses and massages his temple. Then, Miska touches Ville with his fist. It is as though Miska is punching Ville, but he does it very carefully. Ville does not do or say anything during or after the punch. Miska places his head in Ville's lap again. Ville starts to clap the rhythm on Miska's head. After a while, Miska sits up and watches the other children. He still does not participate.

When the poem ends, Anu starts a discussion about the poem. Suddenly, Miska presses his mouth quickly against Ville's arm. Then Miska starts to punch with his fist on Ville's and Miia's (another child's) legs. Miia is sitting on the other side of Miska. Miia does not pay attention to the punching, but Ville looks at Miska. Miska stops punching Miia's leg but continues to punch Ville's. Ville punches Miska on the knee. Ville wrinkles his face and whispers, 'Ouch, ouch, ouch'.

Ville starts to pat Miska's leg with his forefinger. Miska grabs Ville's hand and holds it in his own. Then he lifts his leg onto Ville's lap. Ville takes Miska's leg and puts it between his own legs.

Anu starts to allow the children to go for their lunch, one child at a time, according to the colour of their clothes. 
Anu: Who has red in their clothes?

Ville has lifted his arm onto Miska's shoulders. His other hand is in Miska's [insert

Figure 2] hand. Miska shows Anu his shirt where he has a picture of Superman.

Anu: Superman here is red.

Ville touches Miska's leg and back. Miska gets up. Ville gently pushes Miska from the back. Miska leaves the room.

The institutional context of the preschool is apparent here as circle time is one of the preschool's daily routines. During the circle time, the educator is positioned as an agent and children as objects who are expected to listen to and follow the educator. The circle time can be viewed as 'a symbol of the teaching profession in early education' (Emilson and Johansson, 2013: 57), and one of its aims is to teach children the skills that will be required in school (Williams, 2001). Although circle time is an adult-oriented moment, here, it produces a space for Miska and Ville to touch and relate with each other (see also Prout, 2000). Miska seems to be seeking ways to connect with Ville rather than participating in the activity planned by the educator. In the small story, the children sit side by side on benches and could choose their places. The small story illustrates how the benches and guided circle times intertwine in touch between children and enable children to touch each other as part of the narrative environments of the preschools (Gubrium and Holstein, 2008; Juutinen and Viljamaa, 2016).

Based on embodied expressions, Miska looks as if he is bored. While the other children are participating in the activity, it seems that Miska is trying to fill a boring moment, and he starts to punch the children beside him. Research has shown that children are expected to be active and show initiative towards educators' planned action during circle times (Emilson and Johansson, 2013). In the small story, Miska shows a different kind of active agency and 
initiative, as by touching, he invites other children to join him. Here, the educator enables the touch because she does not interrupt or intervene in what is going on with the children, and thus, her quiet acceptance possibly encourages them to continue. In contrast, the educator's quiet acceptance can also be read as her not noticing the situation or illustrating that it does not disturb her.

Touch can be understood as a dialogue where touch is answered by touch (MerleauPonty, 1962: 315), such as when Ville responds to Miska's touch. However, Miska's touch does not have the same effect on Miia, who does not respond. The dialogue between the children is not verbal. In fact, the children say nothing other than Miska's whispered 'Ouch'. For Merleau-Ponty (1962), there is no boundary between verbal and nonverbal communication. Indeed, he writes that all expression has the same roots: It is an attempt to express how the world is for oneself. Merleau-Ponty continues by saying that communication between people can be viewed as an invitation and experiment towards something that cannot be defined beforehand. This idea of communication is illustrated in the above story, as neither of the children supposedly knows in advance what will be initiated through touch. The result of the invitation and experimentation is accomplished together, in that moment (MerleauPonty, 1962). It seems that Ville is in an in-between space: He is participating with the group following the poem, but Miska's invitation also draws his attention. An intensity of touch develops between Ville and Miska, so that, by the end of the circle time, they sit intertwined with each other and touch each other with their whole bodies.

As the next small story illustrates, touch appeared as an invitation also during free play. The story is from the Roses preschool. Minea and Elviira are three- and four-year-old girls.

\section{Playing doctor}


Elviira is playing with Marja (the educator) on the floor. Elviira is caressing Marja's hand with tools from a doctor's briefcase. Minea sits on a bench close to Elviira and Marja. Elviira turns to Minea and says, 'It will be your turn soon to come for a check-up.' Minea looks at Elviira and Marja and then to the researcher, who is recording.

After a while, Elviira takes the doctor's briefcase and goes to Minea and says, 'Good day'. Elviira sits next to Minea. She turns to open the briefcase, and in doing this, she turns her back on Minea. Minea stands up and moves away. Elviira does not notice this, and turning back, looks confused; she sees that Minea has moved. She notices Minea standing further away. She goes to Minea and puts her arms around her. Minea pushes Elviira away.

Elviira gets the doctor's briefcase from the bench and goes back to Marja. Minea takes a few steps closer. Elviira starts to care for Marja again. Minea comes close to Elviira and kneels beside Elviira's chair. Elviira does not seem to notice.

Marja: Oh, check-up time again. I'm having such good treatment.

Elviira: It is check-up time again.

Minea observes carefully. She takes a tool from the briefcase. Elviira sees this, takes the tool from Minea's hand and gives her another tool. Elviira continues with Marja's treatment. When Elviira has finished, Marja caresses Elviira's hand.

Marja: Thank you. I wonder if Minea would like to be the doctor now. Elviira, would you like to be a patient, would that be nice?

Elviira smiles and Minea takes the briefcase. Elviira takes a doll and goes to sit on Marja's lap. 
Elviira: Here comes a baby to the doctor's appointment.

Minea, who has not said anything during this time, ignores the doll, takes [insert

Figure 3] Elviira's hand and starts to treat it. She is playing to spread lotion on Elviira's hand by gently caressing it.

Here, touch as an invitation begins by Minea directly rejecting Elviira's touch and pushing her away. In earlier research, pushing away has been discussed as children's one way of excluding some children from play (Juutinen et al., 2018). However, in this small story, pushing away appears as a meaningful part of how the children's relation develops. Minea shows agency as her rejection hints willingness to take a more active role in care taking and touch. Yet, the moment requires the educator's active involvement. After watching Elviira play with the educator, Minea comes closer, step by step. At this stage, Marja verbalizes Minea's possible hope about being the doctor and suggests Elviira can be the patient. With the educator's encouragement, Minea eventually joins in the play.

Similarities in experiences enable people to search for connections with each other (Welsh, 2013). In the small story, the children's and the educator's experiences about the healthcare system and its cultures of touch, as well as the materiality, the institutional context and the culture of the preschool and the wider society as part of the narrative environment, invite the children to be in touch in particular ways. For example, the doctor's briefcase and its tools invite Minea to 'spread lotion' on Elviira's hand. The doll is suggested as a 'baby' to be taken care of, but Minea chooses Elviira instead. Elviira also talks about 'a check-up'. In addition, the educator defines that the play is about being in a doctor's appointment. From the viewpoint of embodiment, the bodies appear here as a complex entanglement of the social, the cultural and the biological (Lupton, 2012). 


\title{
Touch as an attempt to control
}

Secondly, touch in children's peer relations appeared as an attempt to control in preschools. Here, children use touch to make other children do as they want to. The next small story takes place in the Lilies preschool during the part of the day when the children can choose their activity. Maria and Aurora are four to five years old.

\begin{abstract}
A big hug
The girls are on their knees, and Maria is holding Aurora on the floor. Laila (the educator) is standing next to the girls. Aurora is trying to get up from the floor, but Maria holds her very tightly. After a brief pause, Aurora gets up. Maria follows her and again hugs Aurora tightly. Maria presses her cheek against Aurora’s cheek. Aurora does not hug back but moans, indicating that she's not happy with the hug. Maria eases up and looks at Aurora with a smile on her face. Maria hugs Aurora again, but Aurora still does not hug back. Aurora looks confused and uneasy.
\end{abstract} Aurora takes a couple of steps towards Laila. Maria is still hugging her tightly. Aurora: Laila, look!

Aurora's hands are wide open; she is not hugging Maria. [Insert Figure 4] Laila: Are you having a big hug? Aurora, do you want to have a hug with Maria? Maria eases up on the hug. Aurora: No! 


\begin{abstract}
Aurora goes to hug Laila. Maria starts to dance around them. Aurora joins in and starts to jump, holding Laila's hand at the same time. Maria stands close to Laila and winds her arms around Laila's leg.
\end{abstract}

Laila: Would you like to find a game to play?

Aurora: I want to read a book.

Educators use touch to control children in preschools (Keränen et al., 2017) which means that at the same time they illustrate practices of touch to children. The attempt to control is here exerted towards the other's body by children as Maria holds Aurora on the floor and does not let her go. After Aurora manages to stand up, the girls look at each other; Maria starts to smile, and her holding turns into hugging. As previous research has shown, hugging is often seen as a good and proper thing to do, and educators usually pay positive attention when children are hugging each other (see also Laws and Davis, 2010). It seems that Maria is aware of this and is able to perform in front of the educator a more appropriate kind of touch in terms of what is expected of her in the institutional context and culture of the preschool (Lanas, 2019).

Maria's attempt to control Aurora remains an attempt because both Maria and Aurora show agency. Aurora refuses Maria's touch in various embodied ways, such as spreading her hands, making facial expressions, being stiff and moaning. Finally, she turns to the educator, saying, 'Laila, look!', which can be interpreted as a way of asking for help. After the educator gives her attention to the situation and asks her question, Maria lets go of Aurora. The educator's question of whether Aurora wants to be hugged can be interpreted in different ways: for Aurora, it seems to indicate that she can choose whether to be hugged, and for Maria, that she should place herself in Aurora's position. Furthermore, Laila's question to Aurora and her response to it, 'No', could work as negative feedback, causing Maria to cease 
her hugging. As children are exploring ways to be in relation to each other, they need assistance from the educators, who give feedback regarding the children's actions (Laws and Davis, 2010).

Jensen (2018) argues that children show closeness by touching and being physically close to each other, whereas distance is shown by keeping bodily distance. However, this small story illustrates how children's touch appears as a more versatile phenomenon than as an expression of closeness. Although Maria and Aurora touch each other, the situation does not appear as a moment of closeness. Rather, Aurora shows willingness to distance herself from Maria.

\section{Touch as a conventional pattern}

Thirdly, touch in children's peer relations appeared as a conventional pattern in preschools, since children seemed to know how to be in touch with each other. This article started with a small story in the Maples preschool, with children of about four to five years old holding hands in a queue; this is an example of touch as a conventional pattern. The story illustrates that the children routinely perform the pattern of holding hands when walking in a queue. Walking hand in hand is so rooted in Iiro and Sara that they will not let go of each other even though it might be uncomfortable to walk with Iiro jumping and bending down while walking. From an educator's perspective, walking hand in hand in a queue appears as one way of controlling the children and keeping them safe (Lupton, 2012; Valentine, 2009).

Another example of touch as a conventional pattern is also from the Maples preschool. The boys in the story are five years old, and the small story takes place during free play. 


\section{Onni knows what to do}

Onni and Kasper are playing with cars on the floor. Heli (educator) comes into the room and says it is time to clean up and have lunch.

Onni: No, I want to play!

Heli: We can continue in the afternoon.

Onni drives his car at Kasper and hits Kasper with the car. Kasper starts to cry. Onni continues to play with the car. Heli is cleaning up further away in the room.

Heli: What happened?

Kasper cries: Onni hit me with that car.

Heli: Did it hurt?

Kasper cries: Yes.

Onni continues driving his car.

Heli: Well, Onni knows what to do. [Insert Figure 5]

Onni goes to Kasper, wraps one arm around him and mumbles: Sorry.

Kasper wipes his tears and goes to Heli.

Heli: Let me see. Where does it hurt?

Kasper shows his hand and says: Here.

Onni has driven his car close to Heli and Kasper. Heli holds Kasper's hand and blows on Kasper's finger.

Heli: There, it is better now. Put the cars away so that we can go to lunch. 
Prior research has illustrated how certain routines and practices are repeated in preschools and how children learn them through being in relations (Williams, 2001). This small story reveals how touch can become a routinized act repeated in the narrative environments of preschools. Touch in children's relations appears here as a conventional pattern: Onni hits Kasper with a car, Kasper starts to cry, and the educator brings up that Onni knows what to do; Onni goes to Kasper, hugs him and apologizes. As such, this pattern of apologizing may have a beautiful meaning and purpose of touch, wiping the hurt away. However, here, the apologizing becomes a routinized act of hugging and saying 'Sorry'. Furthermore, Onni's act of apologizing is not enough to comfort; the educator's comforting touch is still needed. This illustrates the meaning of educators' touch for children (Cekaite and Holm, 2017).

Although touch may become a routinized act, it still affects both the one touched and the one touching, creating a relation between them and touching their inner worlds (Grosz, 1994; Merleau-Ponty, 1962). Yet, the children appear to question here the conventional pattern of apologizing with a hug, since neither of the children seems to want to touch. From the viewpoint of children's agency, Onni's agency appears as an understanding of what apologising means and how to do it conventionally. Onni also has agency in how to hug, and his manner suggests that he is performing the hugging as expected. Kasper seems to lack agency at first as he becomes a mere object of Onni's touch. However, he seeks comfort from the educator.

The above small story illustrates how educators can produce touch between children. The educator's simple phrase, 'Onni knows what to do', reveals that children have been guided on how to act in these kinds of situations. In these routinized acts, educators can 
assume that children already know what to do and trust them to do what is expected (Williams, 2001). Hence, the educator emphasizes here children's agency, and the touch as a conventional pattern directs children to the categories of good behaviour (Lanas, 2019).

\section{Concluding discussion}

This article brought up how touch appears in children's everyday peer relations as an invitation, as an attempt to control and as a conventional pattern. In previous research on children's peer relations, touch has been in a marginal role (e.g. Corsaro, 2003; Hännikäinen, 2015; Juutinen, 2018). This article deepens theoretical understanding about touch in children's peer relations: it shows touch as a multifaceted phenomenon and that the narrative environments of the preschools influence on touch in children's relations. In addition, it shows the meaning of children's agencies as children seek, experiment and challenge ways of touch in these embodied relations. Furthermore, educators have a meaningful role in constructing cultures of touch in preschools.

Previous research has acknowledged wrestling and hitting as well as hugging and being close to each other as a meaningful part in children's relations (Jensen, 2018; Peterson et al., 2018). These acts are also present in our findings. However, viewing touch explicitly in children's embodied relations and in the institutional context of the preschools reveals touch as a multifaceted phenomenon and diverse ways of touch as overlapping. The findings show how hugging in children's peer relations is not only a positively loaded act but can also appear as an attempt to control and as a conventional pattern. Similarly, the findings illustrate that punching and pushing away are not necessarily negatively loaded acts but can work as invitations and through which relations can further develop. 
The findings show how preschools as narrative environments produce, enable and limit touch in the children's everyday peer relations. In preschool, children encounter a narrative environment that is already there: Benches, doctor play, queues, disagreements and hugging provide hints to the children about how to be and how to touch (Merleau-Ponty, 1962; see also Prout, 2000). The idea of preschools as narrative environments includes both the culture of the preschool and the wider culture and the society (Gubrium and Holstein, 2008; Hohti and Karlsson, 2014). One of the aims in preschools is to educate children as proper citizens, also in terms of touch. The findings demonstrate how touch can become a conventional pattern and a routinized act repeated in preschools and how children can be aware of how they are expected to touch in their peer relations (cf. Williams, 2001). On the other hand, preschools enable children to experiment their own ways of touch in peer relations as the examples of touch as an invitation illustrate.

In terms of touch, the children follow the practices created by educators and the wider society. However, the children also challenge these practices and the set limits and experiment ways to connect via touch with each other, appearing as active agents in producing embodied acts of touch in preschools. In addition, children can perform the right kind of behaviour (Lanas, 2019), including in terms of touch.

The findings demonstrate the educators' meaningful role in touch in children's peer relations and in creating cultures of touch in preschools (see also Cekaite and Bergnehr, 2018). The findings show how the educators enable touch in these relations, as the examples of touch as an invitation showed. The educators also guide the children in touch, as the educator did in the stories of hugging turning into controlling and in the examples of touch as a conventional pattern. Finally, the educators maintain practices of touch, which became visible, for example, in patterns like apologizing by hugging and walking in a queue. 
We stress the importance of educators becoming aware of the cultures of touch that exist in preschools and society in general. Touch can play a big role when children invite each other to share something; when asking, answering, suggesting and making sense together; or when controlling. As touch needs to be interpreted based on the context and situation, it is important that educators have a wide understanding of touch in children's peer relations. Furthermore, educators — along with children, their families and the wider society—are creating and producing preschools' cultures of touch, which are continuously re-created.

In evaluating our research process, we stress its dialogical nature: Joint regular discussions deepened the analysis and interpretations (Heikkinen et al., 2007). Video recordings enabled us to study how touch appears as naturally occurring in children's everyday peer relations in institutional contexts (Cekaite and Berghner, 2018). It is worth noting that the video camera captured only one instance of touch between the children in the Anemones preschool. This reminds us that, while video recording, the researcher is forced to decide where to direct the camera. Hence, it is impossible to capture everything that is happening in the preschools, including all the touches in children's relations.

Children carry touches in their bodies from the cultures in which they live, including the preschool, society and family cultures, to name a few. As Uitto and Estola (2009) write, all these touches can leave a memory mark on a child's body. Therefore, touch and its meaning in children's everyday lives in preschools and peer relations need to be fully acknowledged and appreciated.

\section{Acknowledgements}

We are grateful to Anniina Holappa, who drew the pictures for this article. 


\section{References}

Alanen L (2010) Editorial: Taking children's rights seriously. Childhood 17(1): 5-8. DOI: $10.1177 / 0907568209361011$.

Aslanian T (2018) Embracing uncertainty: a diffractive approach to love in the context of early childhood education and care. International Journal of Early Years Education 26(2): 173-185. DOI: 10.1080/09669760.2018.1458604.

Bamberg M and Georgakopoulou A (2008) Small stories as a new perspective in narrative and identity analysis. Text \& Talk 28(3): 377-396. DOI: 10.1515/TEXT.2008.018.

Carlson FM and Nelson BG (2006) Reducing aggression with touch. Dimension of Early Childhood 34(3): 9-16.

Cekaite A (2018) Microgenesis of language creativity: Innovation, conformity and incongruence in children's language play. Language Sciences 65: 26-36. DOI: 10.1016/j.langsci.2017.01.007.

Cekaite A and Bergnehr D (2018) Affectionate touch and care: Embodied intimacy, compassion and control in early childhood education. European Early Childhood Educations Research Journal 26(6): 940-955. DOI: 10.1080/09669760.2017.1414690. 
Cekaite A and Björk-Willén P (2012) Peer group interactions in multilingual educational settings: Co-constructing social order and norms for language use. International Journal of Bilingualism 17(2): 174-188. DOI: 10.1177/1367006912441417.

Cekaite A and Holm MK (2017) The comforting touch: tactile intimacy and talk in managing children's distress. Research on Language and Social Interaction 50(2): 109-127. DOI: 10.1080/08351813.2017.1301293.

Christensen PH (2000) Vulnerable bodies. In: Prout A (ed) The Body, Childhood and Society. Basingstoke: Macmillan, pp. 38-58.

Cigales M, Field T, Hossain Z, Pelaez-Nogueras M and Gewitrtz J (1996) Touch among children at nursery school. Early Child Development and Care 126(1): 101-110. DOI: $10.1080 / 0300443961260107$.

Classen C (2005) The Deepest Sense: A Cultural History of Touch. Urbana: University of Illinois Press.

Corsaro WA (2003) We're Friends, Right?: Inside Kid's Culture. Washington, DC: Joseph Henry Press.Thousand Oaks, CA: Sage.

Emilson A and Johansson E (2013) Participation and gender in circle-time situations in preschool. International Journal of Early Years Education 21(1): 56-69. DOI: 10.1080/09669760.2013.771323. 
Field T (2014) Touch, 2nd ed. Cambridge, MA: Bradford.

Fulkerson M (2014) The First Sense: A Philosophical Study of Human Touch. Cambridge, MA: MIT Press.

Georgakopoulou A (2015) Small stories research. Methods - analysis—outreach. In De Fina A and Georgakopoulou A (eds) The Handbook of Narrative Analysis. Chichester: Wiley, pp. $255-271$.

Grosz E (1994) Volatile Bodies: Toward a Corporeal Feminism. Bloomington: Indiana University Press.

Gubrium JF and Holstein JA (2008) Analyzing narrative reality. Los Angeles: Sage Publications.

Heikkinen HLT, Huttunen R and Syrjälä L (2007). Action research as narrative: Five principles for validation. Educational Action Research 15(1): 5-19.

Hännikäinen M (2018) Values of well-being and togetherness in the early childhood of younger children. In Johansson E and Einarsdottir J (eds) Values in Early Childhood Education: Citizenship for Tomorrow. London: Routledge, pp. 147-162.

Hännikäinen M (2015) The teacher's lap-a site of emotional well-being for the younger children in day-care groups. Early Child Development and Care, 185(5): 752-765. DOI: 10.1080/03004430.2014.957690. 


\begin{abstract}
Hohti R and Karlsson L (2014) Lollipop stories: Listening to children's voices in the classroom and narrative ethnographical research. Childhood 21(4): 548-562. DOI: $10.1177 / 090756821496655$.
\end{abstract}

Jensen SV (2018) Difference and closeness: Young children's peer interactions and peer relations in school. Childhood 25(4): 501-515. DOI: 10.1177/0907568218803437.

Juutinen J, Puroila AM and Johansson E (2018) 'There is no room for you!' The politics of belonging in children's play situations. In: Johansson E, Emilson A and Puroila AM (eds) Values Educations in Early Childhood Settings-Concepts, Approaches and Practices. International Perspectives on Early Childhood Education and Development 23. Cham: Springer, pp. 249-264.

Juutinen J and Viljamaa E (2016) A narrative inquiry about values in a Finnish preschool: The case of traffic lights. International Journal of Early Childhood 48(2): 193-207. DOI: $10.1007 / \mathrm{s} 13158-016-0165-1$.

Keränen V, Juutinen J and Estola E (2017) Kosketus kasvattajien kertomuksissa [Touch in educators' stories]. Journal of Early Childhood Education Research 6(2): 249-269.

Kinnunen T and Kolehmainen M (2018) Touch and affect: Analysing the archive of touch biographies. Body \& Society 25(1): 29-56. DOI: 10.1177/1357034X18817607. 
Lanas M (2019) Can performing happy childhood be an occupational skill required of students? Childhood 26(2): 250-262. DOI: 10.1177/0907568218823882.

Laws C and Davis B (2010) Poststructuralist theory in practice: Working with 'behaviorally disturbed' children. Qualitative Studies in Education 13(3): 205-221.

Lieblich (2014) About Amos: Reading with our heart. Narrative Works 4(1): 114-124.

lisahunter and emerald e (2017) Sensual, sensory and sensational narratives. In: Dwyer R, Davis I and emerald e (eds) Narrative Research in Practice. Stories from the Field. Singapore: Springer, pp. 141-157.

Lupton D (2012) Infant embodiment and interembodiment: A review of sociocultural perspectives. Childhood 20(1): 37-50. DOI: 10.1177/0907568212447244.

Manning E (2007) Politics of Touch: Sense, Movement, Sovereignty. Minneapolis: University of Minnesota Press.

Merleau-Ponty M (1962) Phenomenology of Perception. Translated by C Smith. London: Routledge \& Kegan Paul.

Merleau-Ponty M (1993) Indirect language and the voices of silence. In: Johnson GA and Smith MB (eds) Merleau-Ponty Aesthetics Reader: Philosophy and Painting. Evanston: Northwestern University Press, pp. 76-120. 
Mäkelä J (2005) The importance of touch in development of children. The Finnish Medical Journal 60: 1543-1549.

National core curriculum for early childhood and care in Finland. (2018) Helsinki: Finnish National Board of Education.

Ochs E and Capps L (2001) Living Narrative: Creating Lives in Everyday Storytelling. London: Harvard University Press.

Palmadottir H, Juutinen J and Viljamaa E (2018) ‘Sharing horizons': Methodological and ethical reflections on video observations. In Johansson E, Emilson A and Puroila AM (eds) Values Education in Early Childhood Settings: Concepts, Approaches and Practices. International Perspectives on Early Childhood Education and Development 23. Cham: Springer, pp. 129-143.

Paterson M (2007) Touching Space, Placing Touch. Farnham: Ashgate.

Peterson SS, Madsen A, Miguel JS and Jang SO (2018) Children's rough and tumble play: Perspectives of teachers in northern Canadian Indigenous communities. Early Years 38(1): $53-67$.

Prout A (2000) Childhood bodies: Construction, agency and hybridity. In: Prout A (ed) The Body, Childhood and Society. Basingstoke: Macmillan, pp. 1-18. 
Puroila AM (2013) Young children on the stage. Small stories performed in day care center. Narrative Inquiry 23(2): 323-343.

Rautio P (2013) Children who carry stones in their pockets: on autotelic material practices in everyday life. Children's Geographies 11(4): 394-408. DOI:

$10.1080 / 14733285.2013 .812278$

Rasmussen K (2004) Places for children - Children's places. Childhood 11(2): 155-173. DOI: $10.1177 / 0907568204043053$

Repo L and Repo J (2016) Integrating bullying prevention in early childhood education pedagogy. In: Saracho O (ed) Contemporary Perspectives on Research on Bullying and Victimization in Early Childhood Education. Charlotte: Information Age Publishers, pp. 273294.

Riessman CK (2008) Narrative Methods for the Human Sciences. Thousand Oaks: Sage.

Springgay S (2008) Body Knowledge and Curriculum. Pedagogies of Touch in Youth and Visual Culture. New York: Peter Lang.

Uitto M and Estola E (2009) Gender and emotions on relationships: A group of teachers recalling their own teachers. Gender and Education 21(5): 517-530. DOI: $10.1080 / 09540250802667591$. 
Valentine G (2009) Children's bodies: An absent presence. In: Colls R and Hörschelmann K (eds) Contested Bodies of Childhood and Youth. Basingstoke: Palgrave, pp. 22-37.

Welsh T (2013) The Child as a Natural Phenomenologist: Primal and Primary Experience in Merleau-Ponty's Psychology. Evanston: Northwestern University Press.

Williams P (2001) Preschool routines, peer learning and participation. Scandinavian Journal of Education 45(4): 317-339. DOI: 10.1080/00313830120096743. 


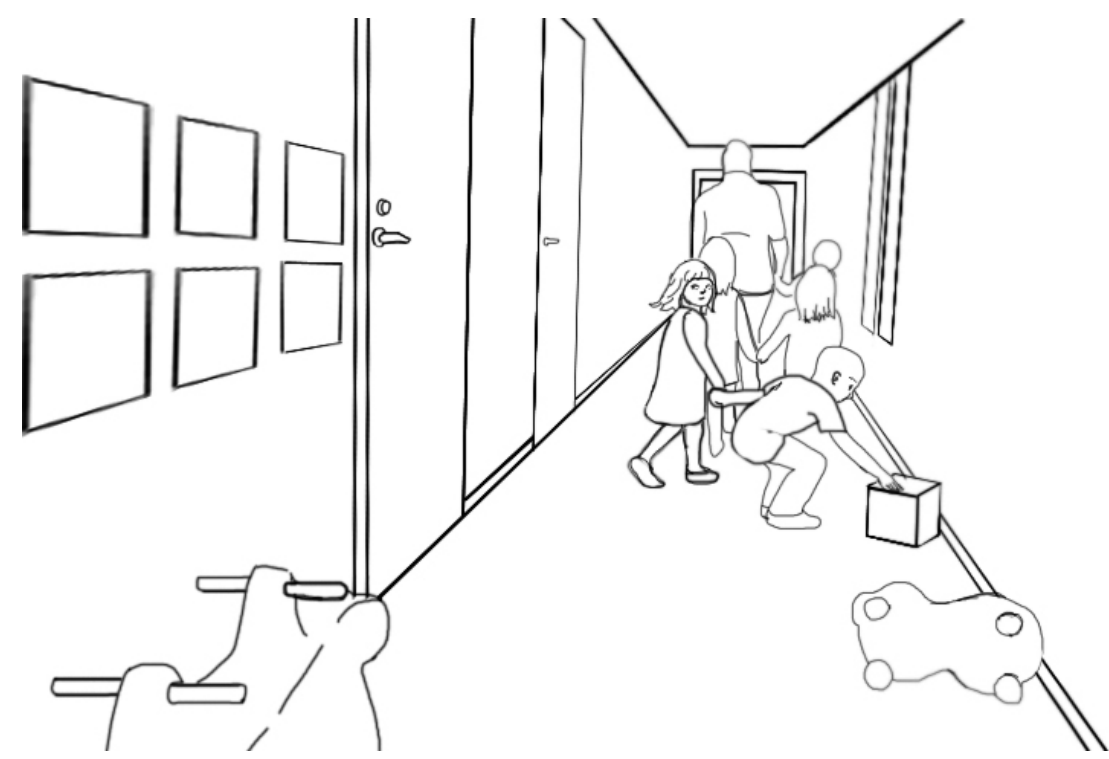

Figure 1 Walking in a queue $301 \times 169 \mathrm{~mm}(72 \times 72$ DPI $)$ 


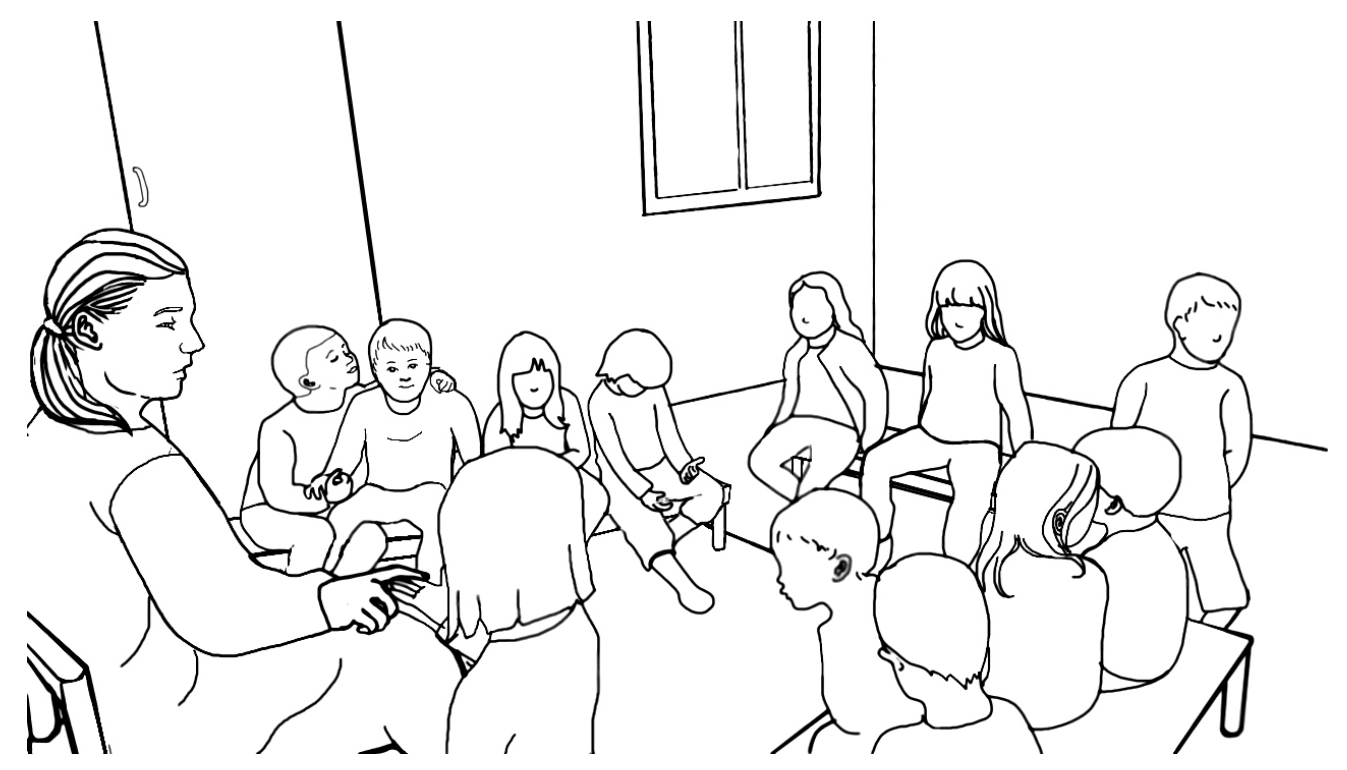

Figure 2 Ville and Miska

$451 \times 254 \mathrm{~mm}(72 \times 72$ DPI) 


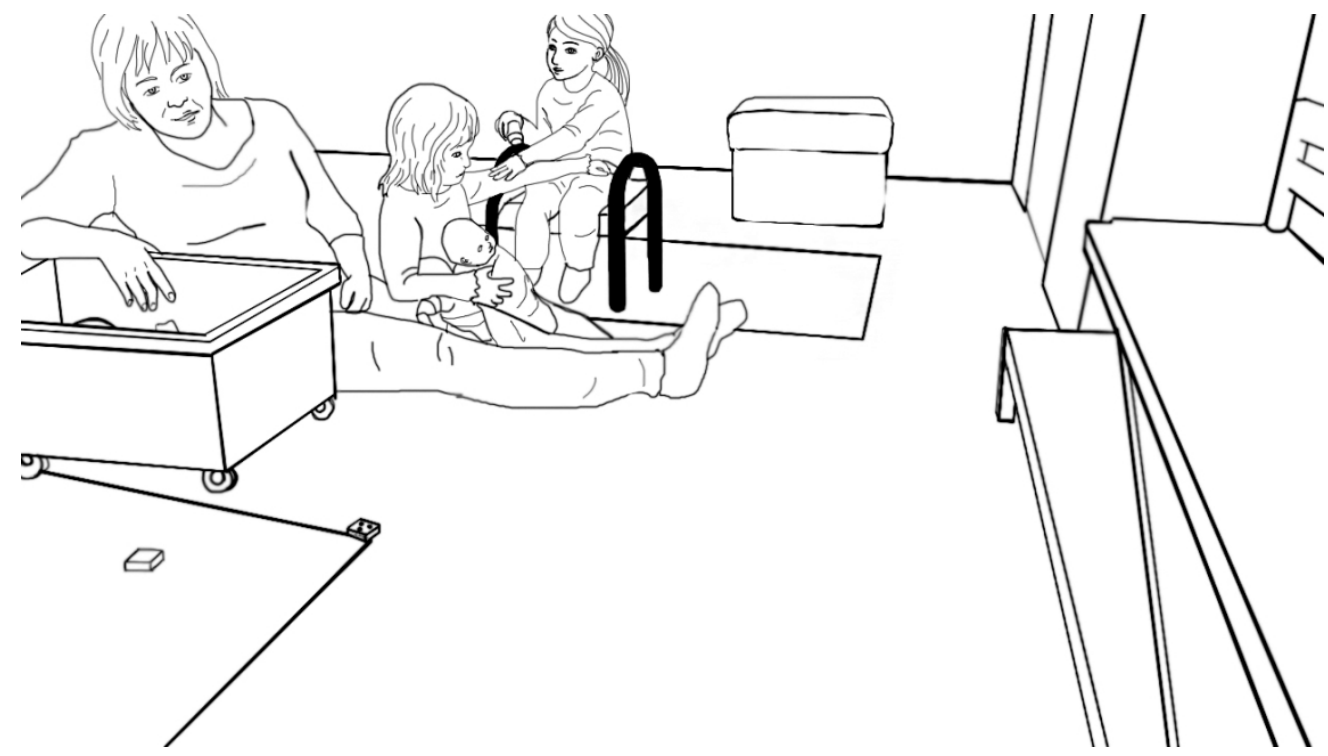

Figure 3 Playing doctor

$451 \times 254 \mathrm{~mm}(72 \times 72$ DPI $)$ 


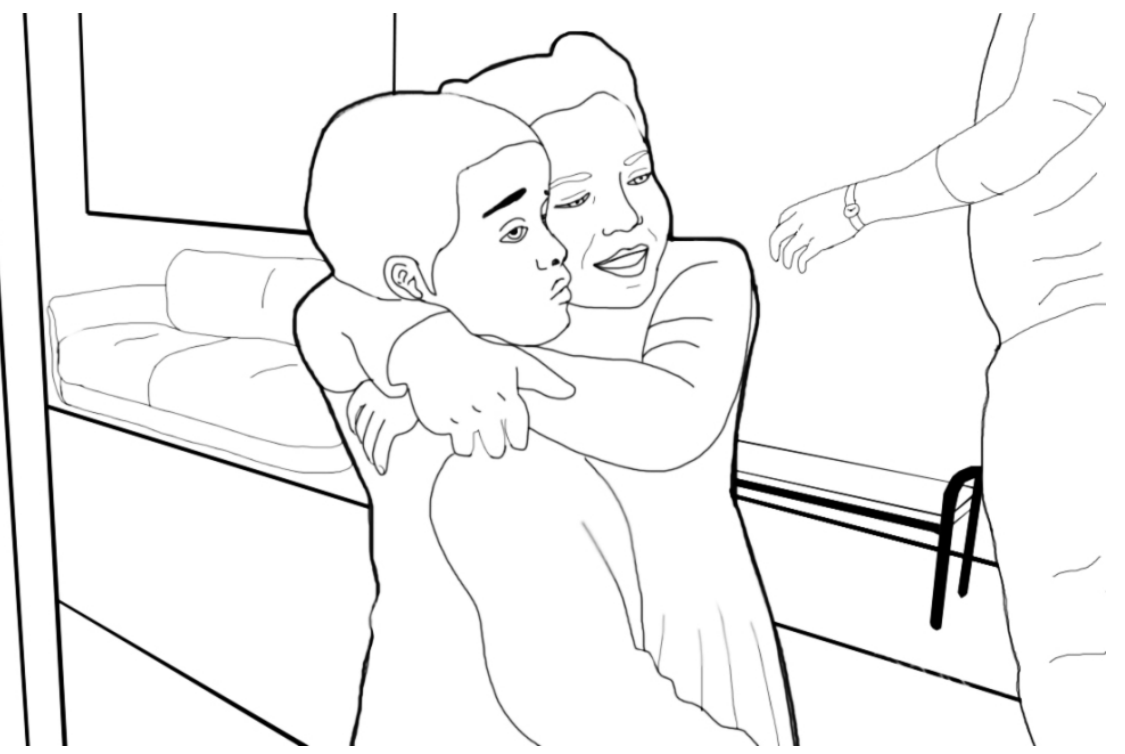

Figure 4 A Big hug $451 \times 254 \mathrm{~mm}(72 \times 72$ DPI $)$ 


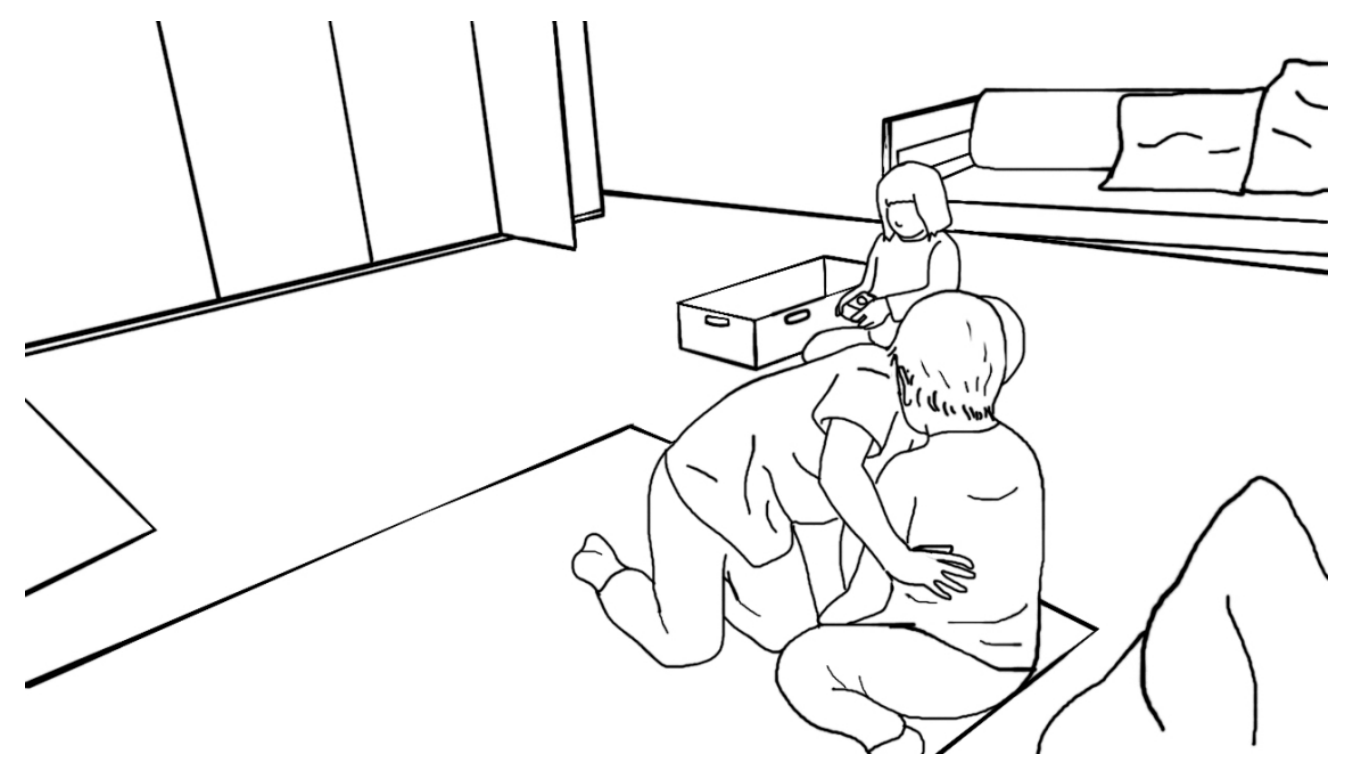

Figure 5 Onni knows what to do $451 \times 254 \mathrm{~mm}(72 \times 72$ DPI) 